\title{
Sensory Polymers for Electron-Rich Analytes of Biological Interest
}

\author{
Youngmi Kim and Timothy M. Swager* \\ Department of Chemistry and Institute for Soldier Nanotechnologies, Massachusetts \\ Institute of Technology, Cambridge, Massachusetts 02139 (USA)
}

\section{Supporting Information}

Materials and Methods. Amino acids and serotonin and dopamine hydrochlorides were purchased from Aldrich. Chicken egg white lysozyme (MW 14,307) was purchased from Sigma. All other chemicals were of analytical grade. Aqueous solutions were always freshly prepared with deionized water. Neurotransmitter solutions were used immediately after preparation. UV-vis absorption spectra were obtained from HewlettPackard 8452A diode array or Cary 50 UV-visible spectrophotometer. Fluorescence spectra were measured with a SPEX Fluorolog- $\tau 2$ fluorometer (model FL112, 450W xenon lamp) equipped with model 1935B polarization kit. The spectra in solution were obtained at $25^{\circ} \mathrm{C}$ using a quartz cell with a path length of $1 \mathrm{~cm}$. 


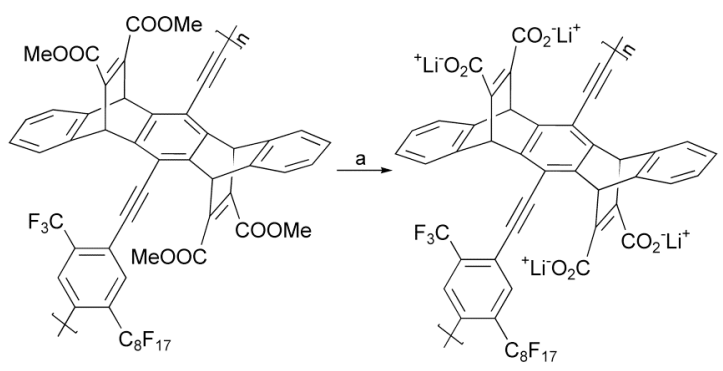

B

$A$

Scheme S1. Synthesis of A: (a) (i) $\mathrm{LiOH}, \mathrm{THF}-\mathrm{H}_{2} \mathrm{O}$ (4:1), $50{ }^{\circ} \mathrm{C}, 48$ h. (ii) dialysis, 3 days.

Synthesis of anionic polymer A (Scheme S1). A $50 \mathrm{~mL}$ round-bottom flask with a magnetic spin bar was charged with $20 \mathrm{mg}$ of neutral polymer $\mathbf{B}(0.017 \mathrm{mmol}$ based on repeat unit). The polymer was dissolved in $8 \mathrm{~mL}$ of THF. To this was added aqueous $\mathrm{LiOH}\left(20 \mathrm{mg}\right.$ in $2 \mathrm{~mL} \mathrm{H}_{2} \mathrm{O}$ ) and the mixture was stirred at $50{ }^{\circ} \mathrm{C}$ for 2 days. After removal of volatile fractions, the reaction mixture was subjected to dialysis against pure water (Pierce Snakeskin ${ }^{\mathrm{TM}}$ MW cutoff: 10,000) for 3 days to give the anionic polymer $\mathbf{A}$ (12 mg, 63\%). ${ }^{1} \mathrm{H}$ NMR spectra for polymers were recorded on a Varian MERCURY (300 MHz) in THF- $d_{8}$. The chemical shift data for each signal are given in units of $\delta$ $(\mathrm{ppm})$ relative to tetramethylsilane $(\mathrm{TMS})$ where $\delta(\mathrm{TMS})=0$, and referenced to the solvent residual. The NMR characterization of anionic polymer A was carried out in acid form obtained by treatment of $0.1 \mathrm{~N} \mathrm{HCl}:{ }^{1} \mathrm{H} \mathrm{NMR}\left(300 \mathrm{MHz}, \mathrm{THF}-d_{8}\right): \delta 8.9-8.8$ (br, 1H), 8.7-8.6 (br, 1H), 7.5-7.4 (br, 4H), 7.1-7.0 (br, 4H), 6.5-6.4 (br, 4H), 5.9-4.0 (br, 4H).

Determination of Stern-Volmer Quenching Constants. The fluorescence quenching efficiency was monitored by measuring the fluorescence intensity of the polymer $\mathbf{A}$ upon addition of the quencher. In order to determine $\mathrm{S}-\mathrm{V}$ constants, a solution of polymer $\mathbf{A}$ in 
phosphate buffer (100 mM, pH 7.4) was titrated with aliquots from a stock solution of the quencher-containing polymer in order to keep the concentration of polymer constant during the titration. The Stern-Volmer quenching constants were determined by the fluorescence intensity at maximum emission wavelength using the following equation: $\mathrm{F}^{0} / \mathrm{F}=1+K_{\mathrm{SV}}[\mathrm{Q}]$

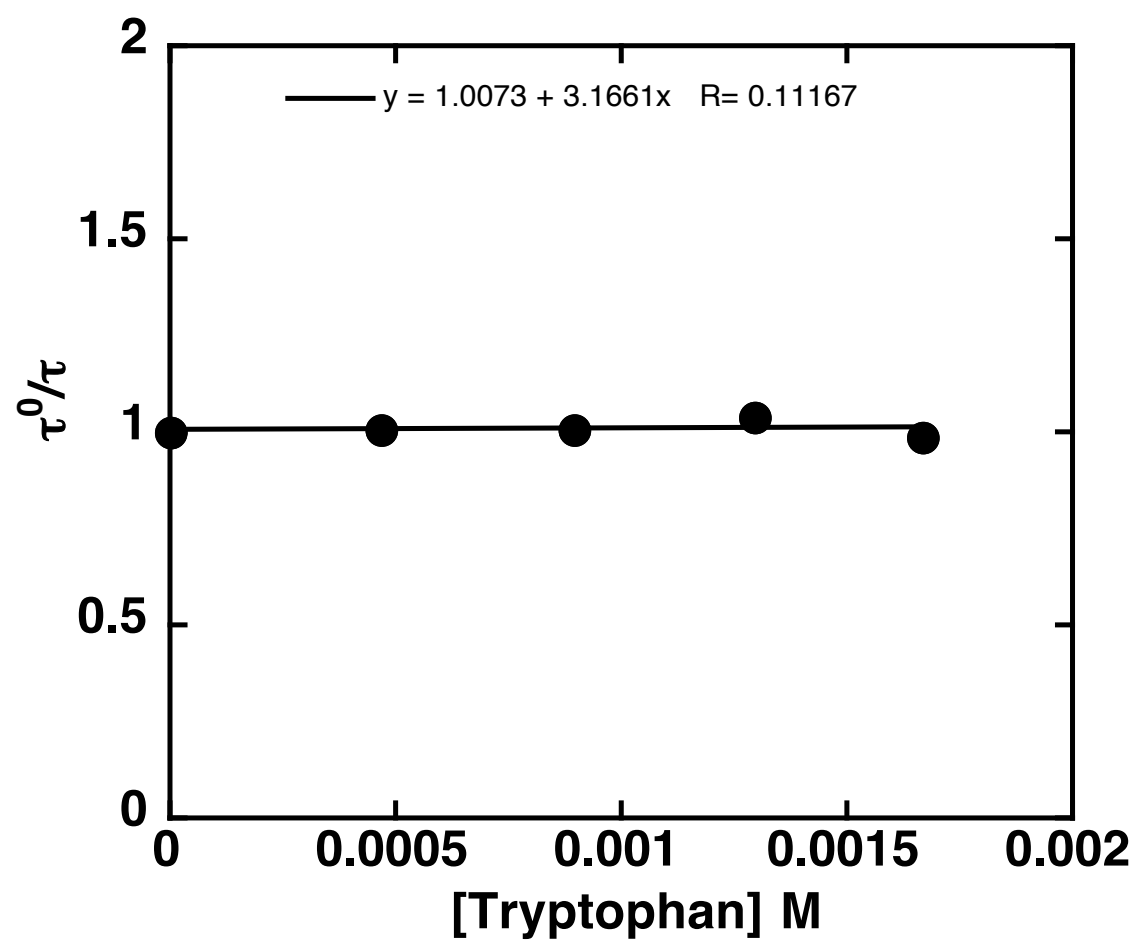

Figure S1. Stern-Volmer measurements of tryptophan quenching as a function of lifetime show no variation indicating a purely static quenching mechanism. 